\title{
Anatomic Study of Complex Anomalies of the Digastric Muscle and Review of the Literature
}

\author{
By \\ Mustafa F. SARGON*, Selda ÖNDEROĞLU**, H. Selçuk SÜRÜCÜ*, \\ Alp BAYRAMOĞLU***, Deniz DEMIRYÜREK*** and Hakan ÖZTÜRK*** \\ *Assistant Professor in Department of Anatomy, Faculty of Medicine, Hacettepe University, Ankara, Turkey \\ ** Associate Professor in Department of Anatomy, Faculty of Medicine, Hacettepe University, Ankara, Turkey \\ *** Research Fellow in Department of Anatomy, Faculty of Medicine, Hacettepe University, Ankara, Turkey \\ - Received for Publication, November 13, 1998 -
}

Key Words: Digastric muscle, Anatomy, Complex anomalies, Human cadaver

\begin{abstract}
Summary: The digastric muscles of 99 cadavers were examined bilaterally. In 5 of them, the digastric muscles showed different types of complex abnormalities. These complex anomalies should be kept in mind in functional studies involving the floor of mouth and evaluating the same structures with CT and MR imaging. Secondly, the embryological basis of the isolated anomalies of the anterior digastric muscle with respect to its occurrence together with the mylohyoid muscle stressed in this article needs further studies of their development from the first branchial arch.
\end{abstract}

Normal anatomy and anomalies of the digastric muscle have been well documented ${ }^{1-6)}$. However there is limited data on the development of this muscle which is a derivative of the first branchial arch together with mylohyoid muscle ${ }^{5,7,8}$. With the advent of the modern techniques such as CT and MR, the importance of normal variants and anomalies in the floor of mouth have become significant. This study stresses the importance of different types of anomalies of the anterior digastric muscle from the embryological as well as the clinical point of view.

\section{Materials and Methods}

58 male and 41 female, a total of 99 cadavers were dissected bilaterally. The submental region was dissected by routine technique and the digastric muscles were examined. In 5 of the cadavers, the digastric muscles showed different types of abnormalities.

\section{Results}

95 of the specimens had normal anterior and posterior bellied digastric muscles, but in 5 of the cadavers the anterior belly of the digastric muscle showed abnormalities as explained as follows.

In the submental region of a 58 year-old female cadaver, abnormal digastric muscles were observed bilaterally (Fig. 1a). On the right side, the two anterior bellies originated from the mandible's digastric fossa. From these bellies, the one laterally located was the normal anterior belly which fused with the posterior belly of the digastric muscle by an intermediate tendon and attached to the greater horn of the hyoid bone. The one medially located was an accessory belly and it attached to the accessory belly of the left digastric muscle and to the body of the hyoid bone. On the left side of the cadaver, the anterior belly of the digastric muscle showed a more complicated arrangement. There were also two anterior bellies on this side originating from the mandible's digastric fossa. From these bellies, the lateral one was the normal anterior belly, but it fused with the posterior belly by a long intermediate tendon and attached to the greater horn and body of the hyoid bone. The medial one 
was an accessory belly and it crossed the accessory right anterior belly anteriorly and attached to the intermediate tendon of the right side. There were also two accessory anterior bellies originating from the intermediate tendon on the left side. From these bellies, the superior one attached to the medial accessory left anterior belly while the inferior one attached to the medial accessory left anterior belly and to the body of the hyoid bone (Figs. 1a and 1b). The anterior digastric muscle had no relation with the mylohyoid muscle. The posterior bellies were normal on both sides.

In the submental region of a 63 year-old female cadaver, abnormal digastric muscles were observed bilaterally (Fig. 2a). On the right side, the two anterior bellies originated from the mandible's digastric fossa. From these bellies, the lateral one was the normal anterior belly, which fused with the posterior belly of the digastric muscle by an intermediate tendon and held to the greater horn of the hyoid bone. The medial one was an accessory belly and it divided into right and left accessory bellies. The right accessory belly attached to the intermediate tendon of the right side and the left accessory belly inserted to the intermediate tendon of the left side. The right and left accessory bellies also inserted to the hyoid bone. On the left side, three anterior bellies were present and they originated from the mandible's digastric fossa. From these three bellies, the most medial belly and the intermediate belly inserted to the muscle fibers of the left accessory belly, which coursed from the right side. The most lateral belly attached to the intermediate tendon on the left side (Figs. 2a and $2 b)$. The anterior digastric muscle had no relation with the mylohyoid muscle. The posterior bellies were normal on both sides.

In the submental region of a 61 year-old male cadaver, an accessory anterior belly was observed between the right and left anterior bellies of the digastric muscles (Fig. 3a). This accessory anterior belly originated from the mandible's digastric fossa, the area between the origins of the right and left anterior bellies, and it divided into right and left accessory bellies close to its attachment to the hyoid bone. The right accessory belly inserted to the muscle fibers of the right anterior belly and to the hyoid bone. The left accessory belly inserted to the intermediate tendon on the left side and to the hyoid bone (Figs. 3a and $3 \mathrm{~b}$ ). The anterior digastric muscle had no relation with the mylohyoid muscle. The posterior bellies were normal on both sides.

During the gross anatomy dissection of the submental region of a 59 years old male cadaver, we observed abnormal digastric muscles bilaterally
(Fig. 4a). On the right side, two anterior bellies originated from the mandible's digastric fossa. These two bellies united with each other in front of the hyoid bone and they fused with the posterior belly by an intermediate tendon. Secondly an accessory belly originated from the medially located anterior belly in front of the hyoid bone and this accessory belly inserted to the hyoid bone. On the left side, two anterior bellies originated from the mandible's digastric fossa. These two bellies fused with the posterior belly by an intermediate tendon and they also inserted to the body of the hyoid bone (Figs. 4a and 4b). The anterior digastric muscle had no relation with the mylohyoid muscle. The posterior bellies were normal on both sides.

In the submental region of a 65 year-old male cadaver, we observed an anomalous origin and course of the anterior belly of the digastric muscle on the right side and complete absence of the anterior belly of the digastric muscle on the left side (Fig. 5a). In this case, the right anterior belly originated from the mylohyoid muscle and hyoid bone. This abnormal belly fused with the posterior belly of the digastric muscle by an intermediate tendon. On the left side of the cadaver, no anterior belly of the digastric muscle was present. A thin tendon originated from the hyoid bone and the posterior extension of this tendon was the posterior belly of the digastric muscle. The posterior bellies were normal on both sides. Interestingly in this cadaver, we observed an abnormal, undefined muscle on the left side of the submental region. This muscle originated from the mandibular arch, coursed in the fatty and loose connective tissue of the submental region and blended with the platysma muscle (Figs. $5 a$ and $5 b)$.

\section{Discussion}

Since Mac.Alister (1882; as cited by Michna, $1989)^{9)}$, Testut (1884; as cited by Michna, 1989) ${ }^{9)}$ and Le Double (1897; as cited by Ziolkowski et al., $1983)^{10)}$, it is known that the anterior digastric muscle shows great variability in its form and attachment. Additionally the existence of accessory anterior digastric muscles are well documented. Digastric anomalies have been reported to occur between $5.9 \%$ and $53 \%$ in seven anatomical stud$\mathrm{ies}^{4}$. Larsson and Lufkin found anomalous anterior digastric muscle in 2 out of 75 cases in his study by $\mathrm{CT}$ and $\mathrm{MR}^{11)}$. Muraki et al. observed 28 symmetric and 6 asymmetric anterior digastric muscles out of 35 patients examined by $\mathrm{CT}^{12)}$. Although the muscles in the floor of mouth appear symmetric, accessory anterior digastric muscles are more often 
unilateral rather than bilateral. Many authors reported accessory muscle bundles that either fused with the midline raphe of the mylohyoid muscle or crossed the midline. Testut and Latarjet described bilateral and unilateral anomalies of the anterior digastric muscle ${ }^{2)}$. Çelik et al. reported a case with anomalous unilateral digastric muscle with three separate insertions; the most medial of which cross the midline and inserted to the digastric fossa on the opposite side ${ }^{13)}$. That three bellied muscle had no relation with the mylohyoid muscle. In another study the anterior digastric muscle had an accessory belly originating from the digastric fossa and inserting to the hyoid bone ${ }^{14)}$. A complex case was reported by Michna in which the right anterior digastric muscle had an accessory belly whereas there were additional asymmetric accessory bellies of anterior digastric muscle between right and left sides ${ }^{9}$. Uslu et al. found an anterior digastric muscle with bilateral accessory bellies ${ }^{15}$. In the study presented here, all anterior digastric muscles showed bilateral anomalies.

The studies on the anterior digastric muscle are also related to its function and clinical importance. Besides its primary action in opening of mouth the anterior digastric muscle is also involved in a number other functional movements. Electromyographic studies showed a marked activity of the digastric muscles during coughing, breathing, swallowing, forceful opening of mouth against resistance, in unexpected events, in sudden unloading of the mandibular elevating muscles ${ }^{16-22)}$. The complex arrangement of anterior digastric muscle presented here may effect the functional support of this muscle to other muscles in the floor of mouth in above mentioned functions.

The studies on the anomalies of the digastric muscle are achieved mainly in adults. However limited data is present on the development of the anterior digastric muscle. The anterior belly of digastric develops from the mandibular prominence (the ventral part of the first branchial arch) which grows ventromedially to meet its fellow in the midline. The fusion of the anterior digastric with the mylohyoid muscle may be attributed to their common origin ${ }^{5.7,8)}$. Ziolkowski et al. studied human digastric muscle in 120 foetuses aged from 4 to 7 months. They divided the cases into four classes according to their age and considered the shape and size of the muscle bellies and of the intermediate tendon with special consideration to their topography. They found the anterior belly to show much variability and in 9 cases they observed additional anterior bellies. The accessory bellied anterior digastric muscles were observed in the second and fourth age classes of foetuses. This finding may be due to increase in growth rate of anterior digastric muscle in the second and fourth age classes. Those authors did not state the relation between anterior digastric and mylohyoid muscles ${ }^{10}$ ). In 4 of our cases, the anterior digastric muscle had isolated anomalies with no relation to the mylohyoid muscle, although these two muscles grow concomitantly ventromedially to fuse in the midline at the same stages of foetal life.

In one case (case 5) of our study, an additional muscle was detected; a muscle originating from the mandibular arch a derivative of the Meckel's cartilage of the first branchial arch and inserting to the platysma muscle which is a derivative of the second branchial arch.

The pathological lesions of the floor of mouth are evaluated by new imaging modalities such as $\mathrm{CT}$ and $\mathrm{MR}^{23}$. Anatomical anomalies may also be detected by the same methods ${ }^{11}$. Asymmetry of the anterior bellies of the digastric muscles is detected in 6 of 29 asymptomatic patients ${ }^{12}$. Larsson and Lufkin presented anomalies in 2 of 75 asymptomatic patients. Especially structures appearing in the midline, like the anomalous anterior bellies of the digastric muscles crossing to the opposite side, may give the appearance of a mass in the floor of mouth $^{11}$.

Different types of complex anomalies should be kept in mind in functional studies involving the floor of mouth and evaluating the same structures with CT and MR imaging. The embryological basis of the isolated anomalies of the anterior digastric muscle with respect to its occurrence together with the mylohyoid muscle stressed in this article needs further studies of their development from the first branchial arch.

\section{References}

1) Last RJ. Anatomy: regional and applied $1977 ; 6^{\text {th }}$ ed, Edinburgh, Churchill Livingstone, pp 409-414.

2) Testut $L$ and Latarjet A. Traité D'Anatomie Humaine 1948; Paris, G. Doin and Cie, vol 1, pp 834-838.

3) Hollinshead WH. Anatomy for Surgeons 1968; vol. 1, The Head and Neck, $2^{\text {nd }}$ ed, Maryland, Harper and Row. pp 414-416.

4) Waern A. Contribution à la connaissance des muscles interposés entre les ventres antérieurs des digastriques chez l'homme et présentation d'un projet de dénomination pour ceux-ci. Arch Anat Histol Embryol Strasb 1935; 20:325337.

5) Williams PL, Warwick R, Dyson $M$ and Bannister LH. Gray's Anatomy 1989; $37^{\text {th }}$ ed, Edinburgh, Churchill Livingstone, pp 172-173, 584.

6) Rauber A and Kopsch F. Lehrbuch und Atlas der Anatomie des Menschen 1955; vol 1, 19. Aufl, Stuttgart. Thieme.

7) Langman J. Medical Embryology 1969; $2^{\text {nd }}$ ed. Baltimore. Williams and Wilkins Co, p 242.

8) Moore KL. The Developing Human, Clinically Oriented 
Embryology 1988; $4^{\text {th }}$ ed, Philadelphia, W.B. Saunders Co, p 173.

9) Michna H. Anatomical anomaly of human digastric muscles. Acta Anat 1989; 134:263-264.

10) Ziolkowski M, Marek J and Klak A. The human digastric muscle in the fetal period. Folia Morphol 1984; 3:243-249.

11) Larsson SG and Lufkin RB. Anomalies of digastric muscles: CT and MR demonstrations. J Comput Assist Tomogr 1987; 11:422-425.

12) Muraki AS, Mancuso AA, Harnsberger HR, Johnson LP and Meads GB. CT of the oropharynx, tongue base and floor of the mouth: Normal anatomy and range of variations, and applications in staging carcinoma. Radiology 1983; 148:725-731.

13) Çelik HH, Yılmaz E, Atasever A, Durgun B and Taner D. Bilateral anatomical anomaly of anterior bellies of digastric muscles. Acta Anat Nippon 1992; 67:650-651.

14) Sargon MF and Çelik HH. An abnormal digastric muscle with three bellies. Surg Radiol Anat 1994; 16:215-216.

15) Uslu SS, Atilla $\mathrm{S}$, Çelik $\mathrm{HH}$ and İnal $\mathrm{E}$. An important anatomic variation in head and neck region: anomaly of the anterior belly of the digastric muscle. Bull Assoc Anat 1995; 79:39-41.

16) Miles TS and Wilkinson TM. Limitation of jaw movement by antagonist muscle stiffness during unloading of human jaw closing muscles. Expl Brain Res 1982; 46:305-310.
17) Otten E. The control of movements and forces during chewing; in Feeding and the Texture of Food (eds); Vincent JFV and Lillford PJ. 1991; Cambridge Univ Press, pp 123-141.

18) Van Willigen JD, Broekhuijsen ML, Melchior HJ, Karkazis HC, Kossioni A and Heath MR. Digastric muscle response as a function of knowledge of the task to be performed. Archs Oral Biol 1993; 38:113-121.

19) Plesh O, Bishop $B$ and Mc Call WD. Patterns of jaw muscle activity during voluntary chewing. J Oral Rehab 1996; 23:262-269.

20) Karkazis HC, Kossioni A, Heath MR and Van Willigen JD. Anterior digastric muscle responses to sudden unloading of the mandibular elevator muscles in younger and older adults. J Oral Rehab 1993; 20:433-439.

21) Ahlgren $\mathbf{J}$ and Lipke DP. Electromyographic activity in digastric muscles and opening force of the mandible during static and dynamic conditions. Scand J Dent Res 1977; 85:152.

22) König B, Vitti M, Berzin F, Camargo AM and Fortinguera $\mathrm{CRH}$. Electromyographic analysis of the digastric muscle. Ciencia e Cultura 1978; 30:463.

23) Mast HL, Haller JO and Solomon M. Benign lesions of the mandibular and maxillary region in children: Characterization by CT and MRI. Comput Med Imag Graph 1992; 16:1-9. 
Plate I
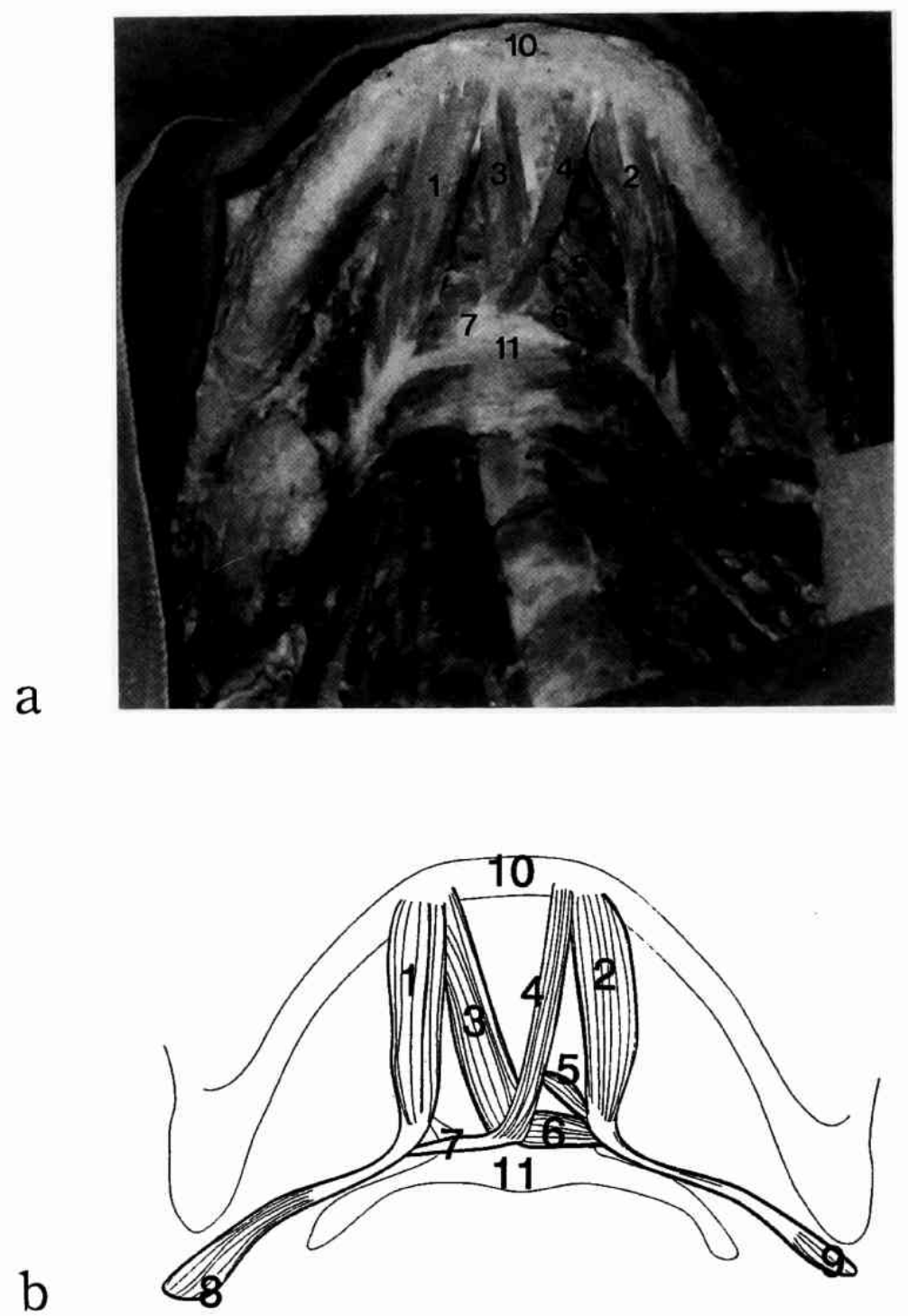

\section{Explanation of Figures}

Plate I

Fig. 1a and 1b. Photomicrograph (Fig. 1a) and schematic drawing (Fig. 1b) of the digastric muscle showing the first complex abnormality described.

1: Right anterior belly of the digastric muscle; 2: Left anterior belly of the digastric muscle; $3,4,5,6:$ Accessory bellies of the digastric muscle; 7: Tendon of the left medial accessory digastric muscle inserting to the right intermediate tendon; 8, 9: Posterior bellies of the digastric muscles; 10: Body of the mandible; 11: Hyoid bone. 
Plate II
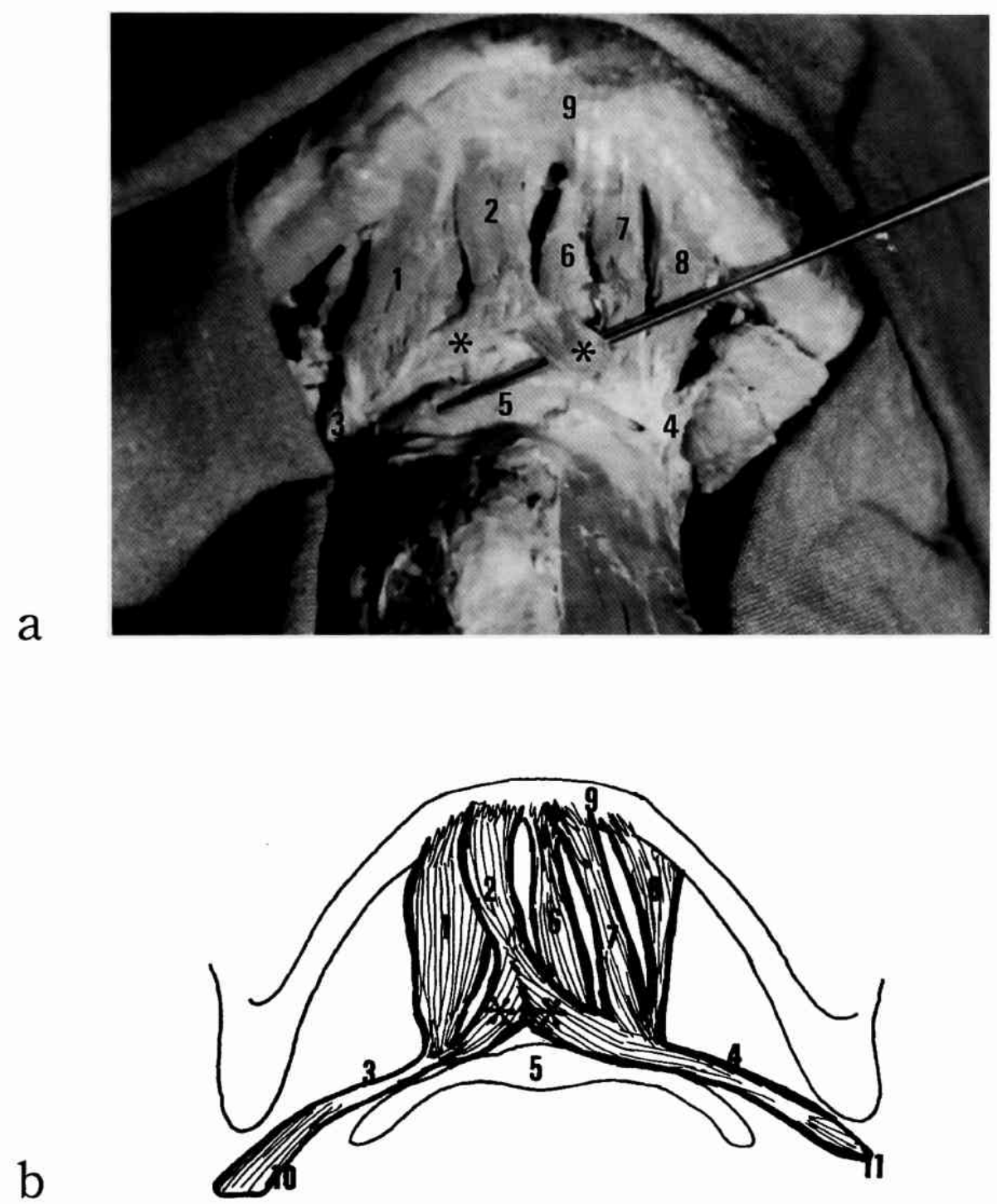

Plate II

Fig. 2a and 2b. Photomicrograph (Fig. 2a) and schematic drawing (Fig. 2b) of the digastric muscle showing the second complex abnormality described.

1: Right anterior belly of the digastric muscle; 2 : Accessory anterior belly which divided into right (*) and left (*) accessory bellies; 3: Right intermediate tendon; 4: Left intermediate tendon; 5: Hyoid bone; 6, 7, 8: Anterior bellies of the digastric muscle on the left side; 9: Body of the mandible; 10, 11: Posterior bellies of the digastric muscles. 

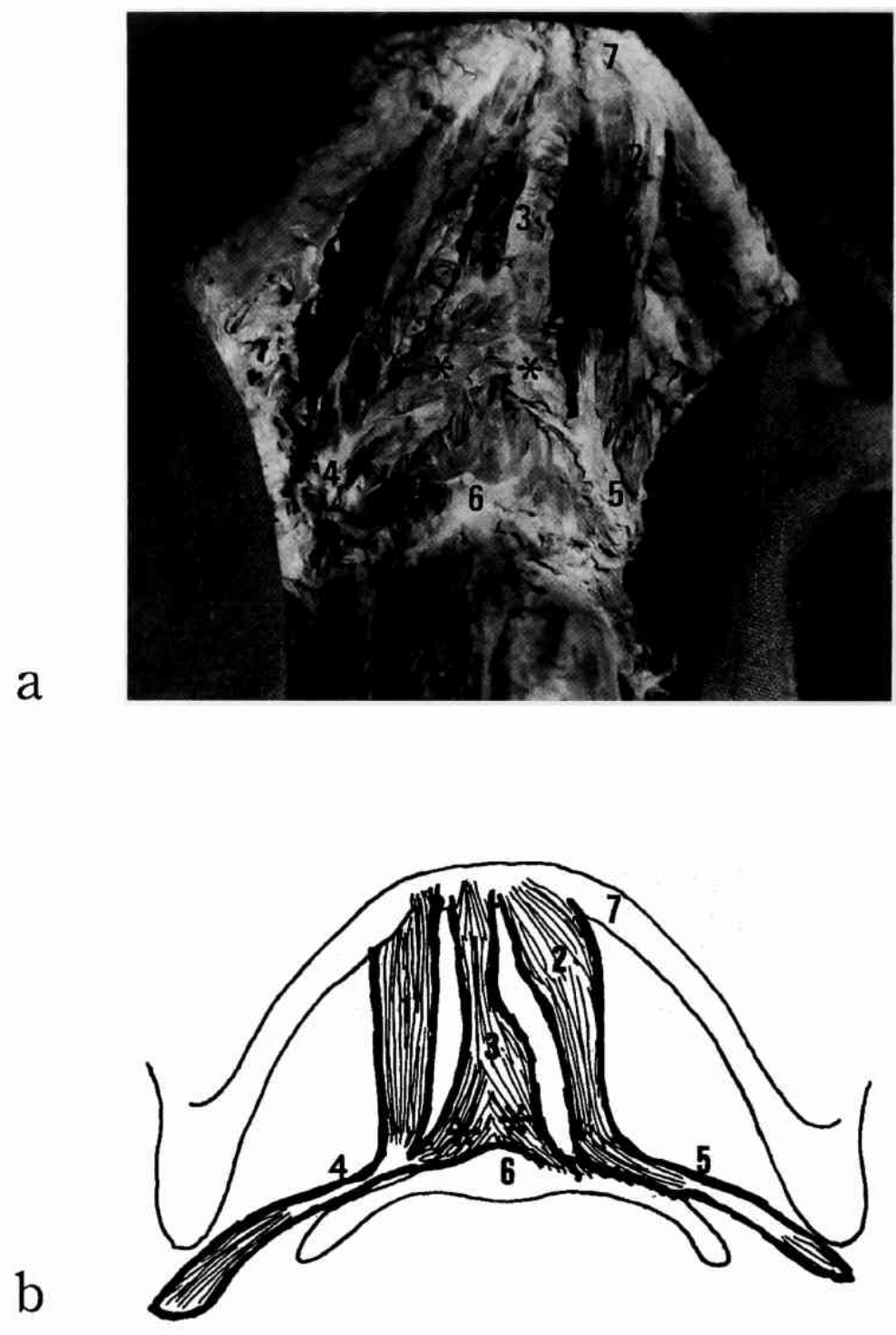

Plate III

Fig. 3a and 3b. Photomicrograph (Fig. 3a) and schematic drawing (Fig. 3b) of the digastric muscle showing the third complex abnormality described.

1: Right anterior belly of the digastric muscle; 2 : Left anterior belly of the digastric muscle; 3 : Accessory anterior belly which divided into right $(*)$ and left $(*)$ accessory bellies; 4: Right intermediate tendon; 5 : Left intermediate tendon; 6: Hyoid bone; 7: Body of the mandible. 
Plate IV
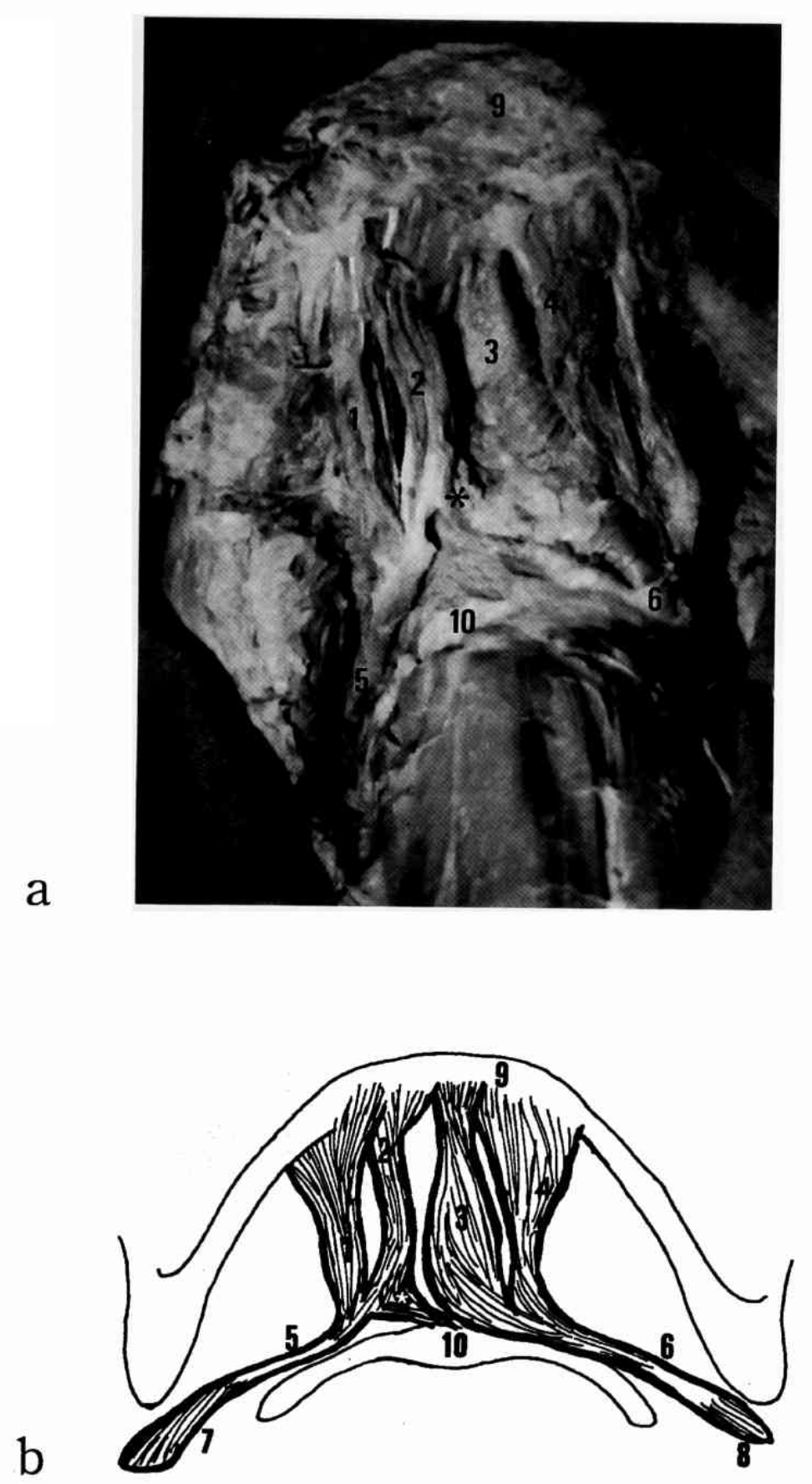

Plate IV

Fig. 4a and 4b. Photomicrograph (Fig. 4a) and schematic drawing (Fig. 4b) of the digastric muscle showing the fourth complex abnormality described.

1, 2: Right anterior bellies of the digastric muscle; 3, 4: Left anterior bellies of the digastric muscle; *: Accessory belly originating from the medially located anterior belly on the right side; 5: Right intermediate tendon; 6: Left intermediate tendon; 7, 8: Posterior bellies of the digastric muscles; 9: Body of the mandible; 10: Hyoid bone. 
Plate V

a
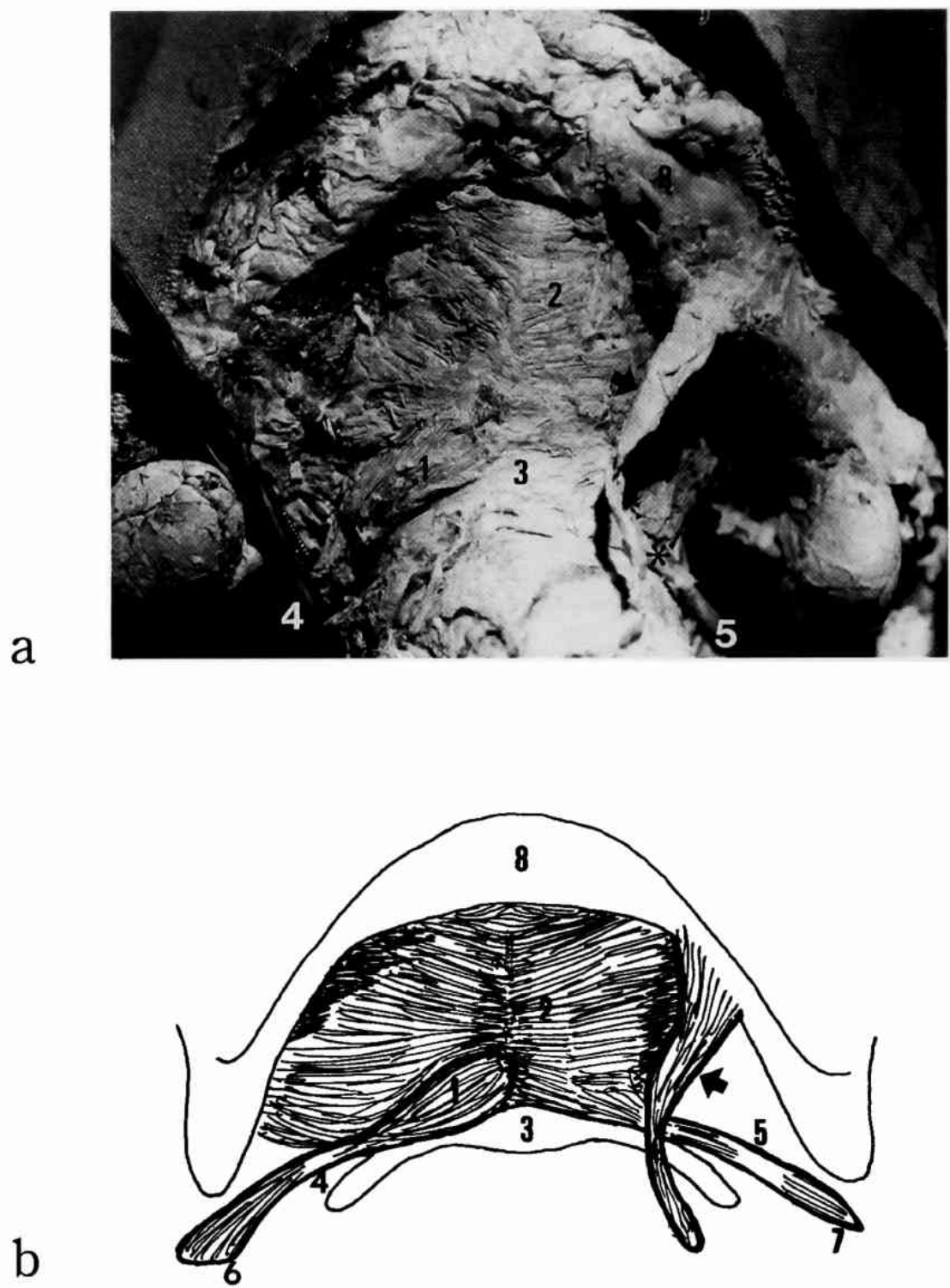

Plate V

Fig. 5a and 5b. Photomicrograph (Fig. 5a) and schematic drawing (Fig. 5b) of the digastric muscle showing the fifth complex abnormality described.

1: Abnormal anterior belly of the digastric muscle on the right side; 2 : Mylohyoid muscle; 3 : Hyoid bone; 4: Right intermediate tendon; 5: Left intermediate tendon; $*$ : Thin tendon originating from the hyoid bone; 6, 7: Posterior bellies of the digastric muscles; 8: Body of the mandible; arrow: Abnormal undefined muscle, observed on the left side of the submental region. 